or hand surgeon. On the other hand it is felt that more emphasis might be placed on the importance of hand positioning in this branch of surgery.

The reviewer realises that to include the treatment of such conditions as cleft lip and palate, hypospadias, burns, pharyngeal defects etc. would involve the author in the production of a major work on plastic surgery.

It is to be hoped nevertheless that he will do this, and that his lucid style, and the informative illustrations of this present work may be extended to cover a wider field.

Let this remark, however, not be construed as a criticism of this book which can be strongly recommended to all surgeons who may be concerned with the problems of providing skin cover.

\section{Recurrent Dislocation of the Shoulder}

by H. F. MOSELEY, M.A., D.M., M.CH., F.R.C.S., F.A.C.S. Illustrated by Helen T. MACARTHUR, B.A. Pp. xii +163 . Illustrated with 10 colour plates, 35 stereoscopic colour photographs and 83 black and white figures. Edinburgh and London: E. \& S. Livingstone. 196r. £6.

For some 30 years the author has studied the surgical anatomy and clinical problems associated with disorders of the shoulder joint. His interest dates from his days as Registrar to Sir Max Page at St. Thomas's Hospital and ever since then he has published numerous articles and monographs which have added considerably to our understanding of a complex and important subject.

The present volume on Recurrent Dislocation of the Shoulder is essentially an extended monograph, but a monograph with a difference. Tucked in a pocket at the back are a series of stereoscopic colour transparencies together with a neatly adapted folding viewer. These photographs are so clear and realistic that the reader feels he is witnessing the actual dissection, without the cost of travelling to Montreal. Perhaps this is a mixed blessing, because Mr. Moseley's technique is obviously that of the meticulous perfectionist, and a journey to watch him would be well spent.

The lavish production has been made possible only with the aid of financial grants from the Ciba Manufacturing Company and from McGill University. Diagrams, photographs, $x$-rays and colour plates abound, and the book is a joy to peruse. It will remain for many years a source of hopeless envy to aspiring authors, but it is so comprehensive and clear that no surgeon who deals with recurrent dislocation of the shoulder can afford to be without it.

\section{Halothane}

by C. R. STEPhen, B.SC., M.D., C.M., and D. M. LitTle, Jr., M.D. Pp. $x+142$, illustrated. Baltimore: The Williams and Wilkins Company. London: Baillière, Tindall \& Cox. 196r. $48 s$.

This monograph on halothane which includes a chapter on the drug in British anæsthetic practice by Dr. J. P. Payne, is a typically Americanised production. For the I I pages of text, I 2 of which are taken up by illustrations or tables, there is an impressive list of 338 references. The style of print is easy to read, though the inclusion of three glossy pages for the sake of a simple rather indistinct photo of a Fluotec vaporiser mounted on a Boyle's machine is perhaps an extravagance.

The twelve chapters review the effects of halothane on the various body systems as well as describing the physical and chemical properties, techniques of vaporisation, compatability with other drugs, clinical administration and usage, and complications.
It is refreshing to find that the authors have often presented more than one point of view when dealing with a controversial agent; and that they have not accepted at face value some of the earlier more exotic claims of the advantages of this agent.

A little more might profitably have been written about the azeotropic mixture of ether and halothane, especially as it is said to have a fairly wide use in the United Kingdom for tonsillectomy.

The main value of this book lies in the fact that it presents, in a succinct manner, a reasonable proportion of the vast literature that has accumulated in the past five years.

Modern Trends in Anaesthesia 2: Aspects of Hydrogen Ion Regulation and Biochemistry in Anaesthesia.

Edited by F. T. Evans, and T. C. Gray. Pp. vii + 219, illustrated. London: Butterworth. 1962. $60 s$.

'Many biochemical subjects', the preface tells us, ' are adequately dealt with in current textbooks of anæsthesia. The intention of this present book is to fill any gaps which there may be and to make up-to-date information readily available'. This is an ambitious intention; ' any gaps which there may be' is a euphemism, 'up-to-date' is a relative term for medical books, and it is doubtful how 'readily available' a f3 volume is likely to be. Nevertheless, the attempt has proved most valuable.

The text is made up of eight chapters of somewhat varying quality: (r) Nomenclature and Presentation of Hydrogen Ion Regulation Data (J. F. Nunn)-a clear and well designed review. (2) The Measurement of $\mathrm{pH}$ and $\mathrm{P}_{\mathrm{co}_{2}}$ (R. F. Woolmer)-also a first rate account of the present position. (3) The Effects of Hypercapnia (J. F. Nunn)-disappointingly ' woolly' after chapter I, especially at first. (4) Hyperventilation (J. S. Robinson) -a rather unbalanced presentation, stressing, not altogether without bias, cerebral effects. (5) Acid-Base Balance in Hypothermia (D. K. Brooks) -a personal view by an advocate of the Drew technique, at times very unfair to the pump-oxygenator. (6) Acid-Base Changes due to Cardiac Bypass (R. S. Jones)-a competent summary. (7) Some Trends in the Biochemistry of Anæsthesia (I. C. Geddes) - a miscellany, including an account of adrenocortical mechanisms, nutrition by the intravenous route, and the biochemistry of massive blood transfusion. (8) The Cholinesterases (H. Lehmann and J. Liddell) - a masterly and welldocumented review.

The editing is unimpressive; one or two of the contributors would have benefited from more help in expressing their meaning clearly and the references, especially for a book of this standard, should have been more carefully checked. 'Physiological Reviews', for example, is abbreviated in three different ways on page ror, and page 79 contains a reference to ' $\mathrm{J}$. Pharmacol.Exp.Theo'. and has 'Anesthesiology' spelled in two different ways; these may be small points, but many comparable solecisms are to be found.

It seems that the publication of reviews of single aspects of a specialty is now to be the policy for "Modern Trends' volumes. The need for this glorified form of journalism, in view of the increasing number of specialised periodicals, may be open to question, but as far as anæsthesia is concerned the high standard set by the contributors to the present volume augurs well for the future of th? series. 